\title{
Nachrichten aus der AO
}

Philip Wilbrandt

\section{3-Länder-Tagung der AOTrauma Deutschland-Österreich-Schweiz (D-A-CH)}

\section{9.-11. Mai 2019, Hotel Radisson Blu, Hamburg}

Liebe Mitglieder und Freunde der AOTrauma Deutschland, Österreich und Schweiz,

wir laden Sie herzlich zur 3-Länder-Tagung unserer 3 AOTrauma-Sektionen nach Hamburg vom 9. bis 11. Mai 2019 ein.

Das wissenschaftliche Programm wird geprägt sein von unseren traditionellen Falldiskussionen und Neuigkeiten von und für unsere Mitglieder. Dafür haben wir mehrere Experten von AOT Education und Community Development eingeladen, die auch individuell die verschiedenen Programme und deren Anwendung vorstellen und Fragen beantworten können.

Zum ersten Mal haben wir unsere OP Personal Teams eingeladen.

Wir freuen uns, viele von Ihnen in Hamburg begrüßen zu dürfen. Der Austausch zwischen den ältesten und aktivs-

\section{Wissenschaftspreis 2018 der deutschen $\mathrm{AO}$}

Auf dem DKOU wurde der Wissenschaftspreis 2018 der Deutschen AO verliehen. Der Preis ist mit 7500,- EUR dotiert. Es gab 10 eingereichte Arbeiten. Herr Dr. Marcel Orth, Homburg/Saar erhielt den Preis für seine Arbeit: „BMP-2-loaded mineral coated microparticles improve bone repair in atrophic non-unions“, die er auf der Preisträgersitzung Nachwuchsförderung der AOTrauma Deutschland im Rahmen des DKOU vorstellen durfte.

Deadline für die nächste Ausschreibung des Wissenschaftspreises ist voraussichtlich der 31. August 2019.

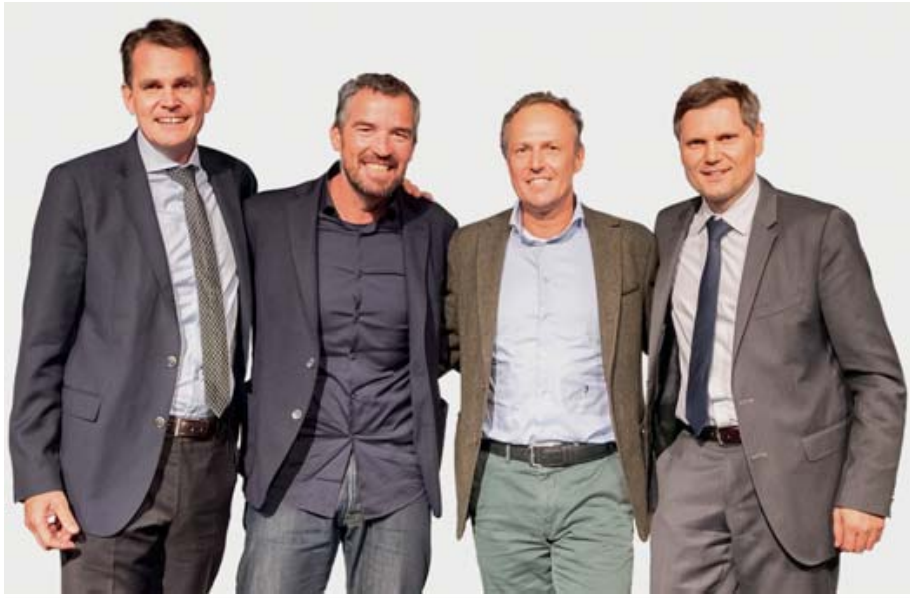

Die Präsidenten Stöckle, Borens und Kralinger sowie Gastgeber Frosch. Quelle: AO Foundation

ten Sektionen der AO lebt vom persönlichen Kontakt und dem kollegialen Gedankenaustausch.

Ulrich Stöckle, Präsident Deutschland

Olivier Borens, Präsident Schweiz

Franz Kralinger, Präsident Österreich Karl-Heinz Frosch, Gastgeber

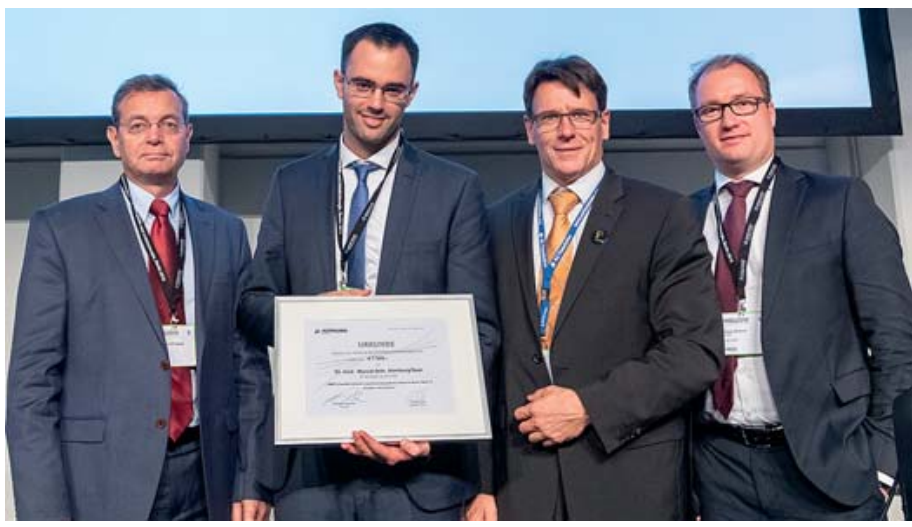

Auswahlkommissionsmitglied Hans-Christoph Pape mit Preisträger Marcel Orth, Research Officer Georg Duda und Auswahlkommissionsmitglied Richard Stange. Quelle: AO Foundation 


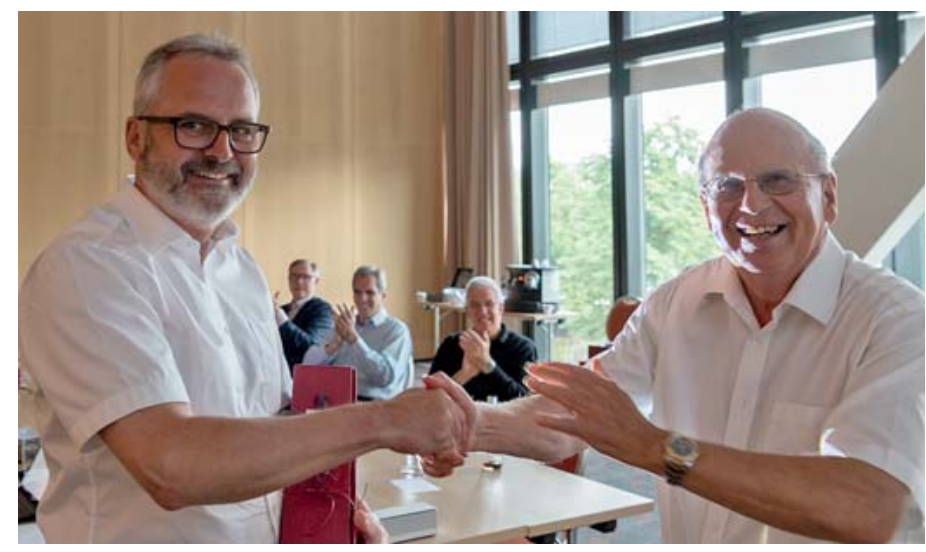

Florian Gebhard wird von Rolf Jeker beglückwünscht. Quelle: AO Foundation

\section{Personalia}

\section{Wahlen AO International}

Florian Gebhard (Ulm) wurde auf dem AOT Stiftungsratstreffen im Juli in Basel zum President-elect der AO Foundation gewählt wurde (Amtszeit als Präsident Juli 2020Juni 2022). Er ist nach Siegfried Weller und Norbert Haas erst der 3. Deutsche, dem diese Ehre zuteil wird.

\section{Bibliografie}

DOI https://doi.org/10.1055/a-0677-3627 OP-JOURNAL 2019; 35: 73-74 @ Georg Thieme Verlag KG Stuttgart · New York ISSN 0178-1715 